\title{
New Media Art as a Vehicle for Research and Innovation
}

\author{
Terry Trickett \\ Trickett Associates \\ Barbican, London, United Kingdom \\ terrytrick@mac.com
}

\begin{abstract}
New media artists have the capability of driving forward innovation on major issues of the day. 'Exceedingly complex' systems (eg. the brain) provide examples of how the inevitable pitfalls and breakthroughs that occur in processes of discovery are of direct concern to new media artists as well as to the scientists, engineers, sociologists and technologists that may be involved. This paper reveals that, in this digital age, the creative processes of art and science are similar to the point of being virtually synonymous. It's this fact that underpins how, through the European Commission's S+T+ARTS (Science + Technology + Arts) initiative and opportunities offered by the Commission's programmes of research and innovation, new media artists can both generate and develop, in cooperation with their scientific and technological counterparts, transformational projects concerned in the exceedingly complex issue of climate change.
\end{abstract}

New media art. Innovation. The brain. The Company. Geometry. Climate change. STARTS.

\section{INTRODUCTION}

The advent of 'new media art' can be regarded as a revolutionary event rather than the outcome of a gradual evolutionary process. Not since the invention of the camera has a new technology come along which has changed the very fabric of art making possibilities on such a grand scale. Now, the almost omnipresent conjunction that exists between the visual arts and digital technology enables new media artists to demonstrate a 'creative curiosity that seeks to explain and express itself through social purpose and technological revolution rather than through beauty alone' (Tofano 2019). This rich seam of creativity, ripe for exploration and development, gives promise of driving forward innovation on the major issues of the day. I see it as being a new-found vehicle for research and innovation which I'm illustrating, in this paper, by reference to my own personal involvement in processes of discovery, both past and present.

Staying in the present for the moment, the particular form of new media art that I adopt for myself in demonstrating a creative curiosity towards 'the brain' is Visual Music. It's by means of my piece 'Brainwaves' (Trickett 2021a) that I illustrate, visually, the 'exceedingly complex' system of the brain and, in this accompanying paper, I aim to describe both the pitfalls and breakthroughs that can occur in the pursuit of knowledge and fundamental understanding of an intractable problem. My hope is that, by providing some insight into these processes of discovery, I will succeed in shining some light on how another exceedingly complex system, climate and the issues affecting its change, can be tackled. But first, I must explain my use of the term 'exceedingly complex' system.

\begin{tabular}{|c|c|c|c|}
\hline SYSTEM & Simple & Complex & $\begin{array}{l}\text { Exceedingly } \\
\text { complex }\end{array}$ \\
\hline \multirow[t]{3}{*}{ Deterministic } & Window catch & $\begin{array}{l}\text { Electronic } \\
\text { digital computer }\end{array}$ & \multirow{3}{*}{ Climate change } \\
\hline & Billiards & $\begin{array}{l}\text { Planetary } \\
\text { system }\end{array}$ & \\
\hline & $\begin{array}{l}\text { Machine-shop } \\
\text { layout }\end{array}$ & Automation & \\
\hline \multirow[t]{3}{*}{ Probabilistic } & Penny tossing & Stockholding & The economy \\
\hline & $\begin{array}{l}\text { Jellyfish } \\
\text { movements }\end{array}$ & $\begin{array}{l}\text { Conditioned } \\
\text { reflexes }\end{array}$ & The brain \\
\hline & $\begin{array}{c}\text { Statistical } \\
\text { quality control }\end{array}$ & $\begin{array}{l}\text { Industrial } \\
\text { profitability }\end{array}$ & THE COMPANY \\
\hline
\end{tabular}

Figure 1: In 1959, UK cyberneticist, Stafford Beer prepared an analysis of comparative systems from 'simple' to 'exceedingly complex'. If he were alive today, almost certainly he would place the words 'climate change' in his 'empty' box.

It was as long ago as 1959, when the UK cyberneticist, Stafford Beer, prepared an analysis of comparative systems (ie. what do organisational systems do and how do they do it) by grading them from simple to complex (Figure 1). He placed only three systems in his 'exceedingly complex' category: 
'the economy', 'the brain' and 'the Company'. Beer's list demonstrates a wry sense of humour which serves to underline the definition of each system's predictability and its susceptibility for control by welltried scientific methods (Beer 1959). A list made today would still contain all three of Beer's exceedingly complex systems but, if he were to be alive now, I feel sure that he would place 'climate' on his 'exceedingly complex' short-list in the knowledge that changes occurring in this system pose a formidable challenge - thus providing a platform where, almost more than anywhere else, there are opportunities for new media artists to drive forward innovation.

\section{TURING PATTERNS}

Before explaining my work on the brain, I'm going back a few years to recapitulate an experience that I now see as being pivotal in bringing my separate interests in the realms of science and new media art closer together. In 2016, I indulged my fascination with Turing Patterns by producing 'Turingalila: Visual Music on the Theme of Morphogenesis' (Trickett 2016). In that piece, I celebrated Turing's prescience by perturbing just two Turing patterns to reveal processes of self-organisation reminiscent of those found in nature (Figure 2) and, in my presentation, I laid stress on the relevance of Turing's morphogen theory in today's world by making special mention of the work of Professor Jeremy Green, a developmental biologist at Kings College, London (Figure 3 ). He is a biologist who has fully embraced the concept of self-organisation in regulatory networks occurring in tandem with the chance outcomes of Darwinian selection (Figure 3). In a meeting with Jeremy, sometime after the completion of Turingalila, he pointed out to me that, at first sight, Turing's disparate inspirational ideas may seem disconnected, one from another; what, for instance, is the link between the mathematical biology of his morphogen theory and artificial intelligence? But where we see separation, Turing would have seen only continuity; the overarching guiding principle of all his work was directed towards modelling the human mind as a machine. For him, the way morphogens drive hundreds of simple steps that make one part of the embryo different from another was an integral part of his lifelong search to establish the mathematical basis of how we think, how human intellectual abilities can be replicated using artificial neural networks.

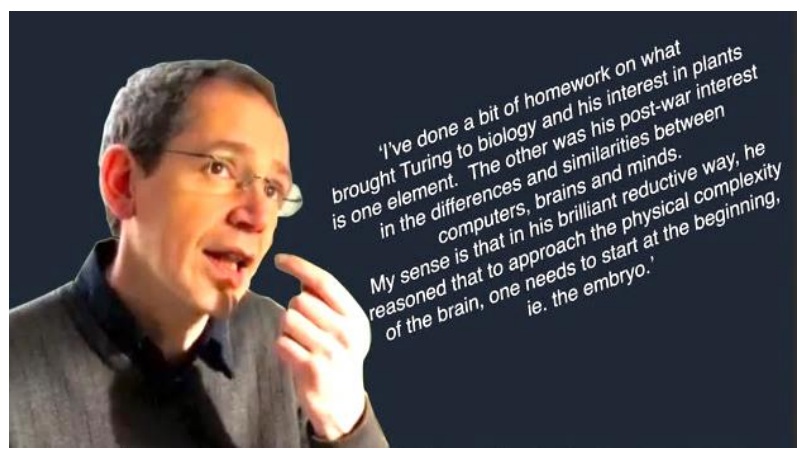

Figure 3: Jeremy Green, Professor of Developmental Biology, King's College, London, is that rare exception, a biologist who has fully embraced the concept of selforganisation in regulatory networks occurring in tandem with the chance outcomes of Darwinian selection.

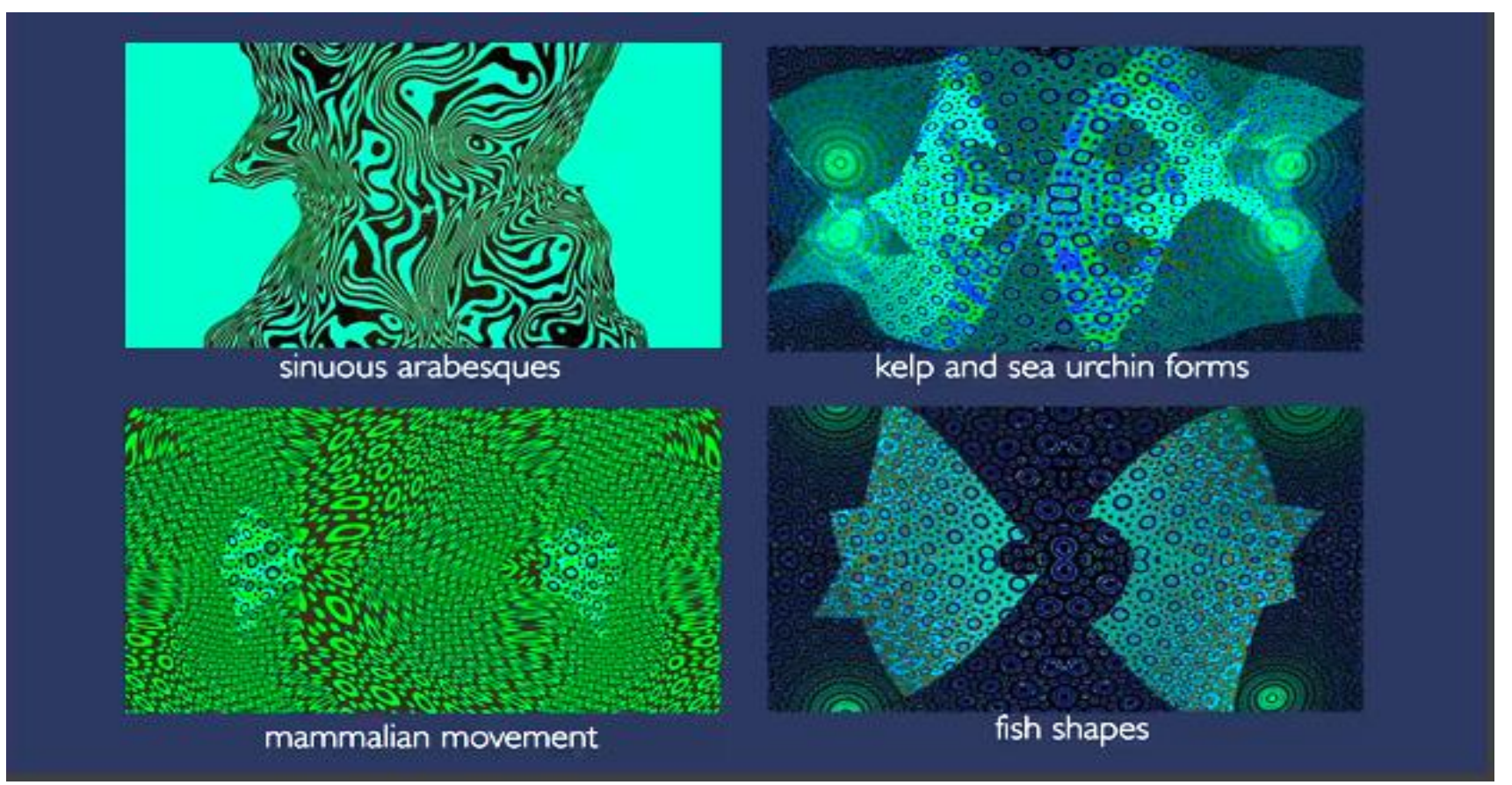

Figure 2: In 'Turingalila', an extraordinary diversity of forms emerged seemingly spontaneously. Apparently, what l'd discovered was a purposeful tool for simulating natural processes. 


\section{UNDERSTANDING COMPLEX ANATOMY}

Little did Jeremy know, at the time, that it was his comments on Turingalila that set me off on a subsequent search into the patterns that underlie how our brains' work. This was a subject that had first captured my imagination when, years earlier, as instigator of the Wellcome Trust's Sci-Art project (1997 - 2006) (Trickett 2015 and 2021b), l'd made contact with Igor Aleksander, Professor of Neural Engineering at Imperial College, London, who regards the brain as being dependent on an unexplored form of engineering - one inspired and controlled by an astonishingly intricate structure or architecture (Figure 4) (Aleksander 2000).

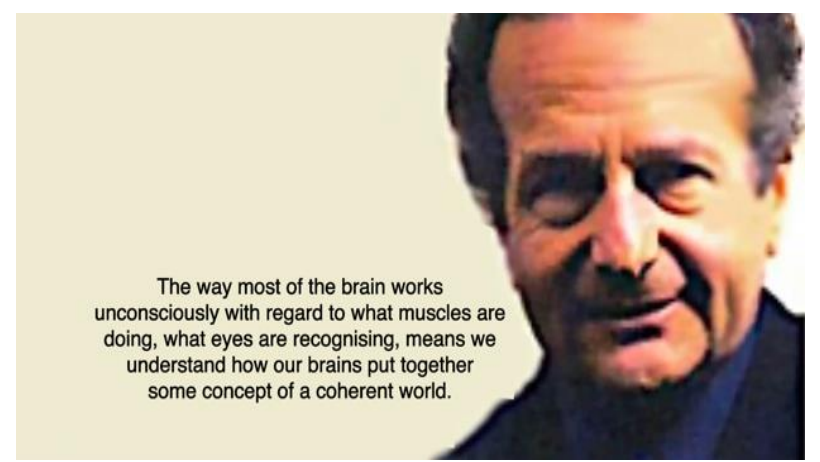

Figure 4: Igor Aleksander, Emeritus Professor of Neural Engineering at Imperial College, London,

regards the brain as being dependent on an unexplored form of engineering - one inspired (and controlled) by an astonishingly intricate structure or architecture.

It was these twin influences, from the realms of developmental biology and engineering, that set me on course to explore, for myself, the astonishingly intricate pattern that underlies our ability to think. (A full explanation of this story can be found in my paper 'As astonishingly intricate architecture: Visual Music of the Brain and Mind' published in Technoetic Arts, Volume 16, Number 1. (Trickett 2018))

To find a clue to the neural pattern of connections hidden within the human brain, I turned to Islamic geometry. Islamic designs can not only 'confound the eye of the beholder' with their complexity but, also, they can provide a geometric clue to solving complex spatial problems. An examination of Muslim buildings in Istanbul, Afghanistan, India and elsewhere reveals patterns based on the knitting together of complex identical geometric forms. The result is a network, where the lines of the mathematical scheme can be regarded as systems of neural communication. By taking a very small section of the brain, as an example, we can begin to see a pattern producing a multitude of ribbons that interweave, one with another, in designs of dazzling complexity (Figures $5 \& 6$ ). It seems to exemplify the type of 'profound order being discovered in large, complex and supposedly random systems' ie. emergent order that Stuart Kauffman believes underlies much of the order seen in organisms today (Kauffman 1995).

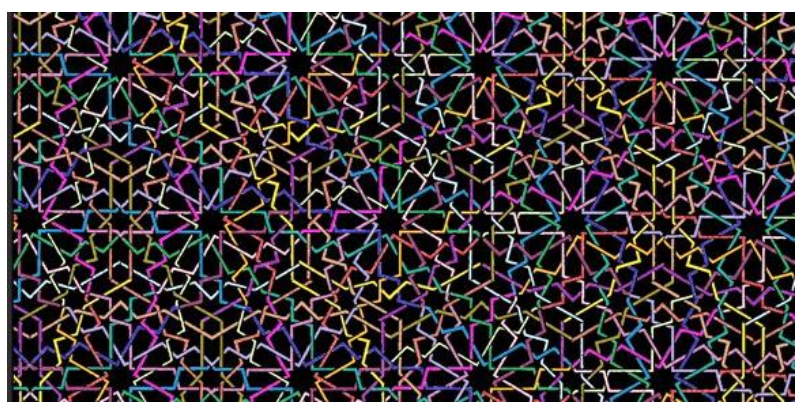

Figure 5: By taking a very small section of the brain as an example, we can begin to see a pattern, based on Islamic geometry, that produces a multitude of ribbons centred on a series of hubs, which closely resemble $11 D$ simplices (see Section 8)

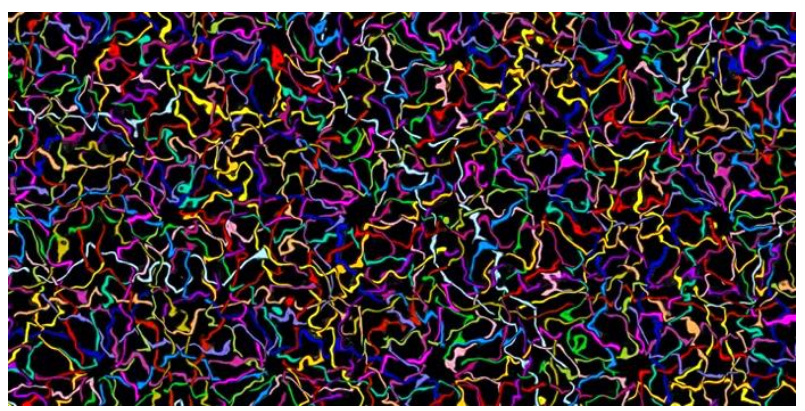

Figure 6: In spite of appearances to the contrary, this is the same pattern distorted by the brain's gyri (hills) and sulci (valleys).

At this point, I'm turning again to Turing and comments made by Jeremy Green when we shared a platform, together with Andy Lomas, digital artist and mathematician, and Jonathan Bowen, computer scientist at an EVA presentation celebrating the genius of Alan Turing (Bowen et al 2018). Each of us, in our different ways, owe a huge debt to Turing; without him we could not do what we do. In this context, Jeremy's comments reveal how his own processes of research are underpinned by Turing's morphogen idea:

For me, Turing's idea provided the missing piece in understanding how complex anatomy appears from the simplicity of a fertilised egg, a single cell. Humans are made of trillions of cells but we're not just big cellular snowballs. We have structure and anatomy: back and front; top and bottom; limbs, guts and brains. That anatomy comes from chemicals shifting around as the embryo develops........ Working with Turing's model showed me something else.......While I could adjust many different variables and set up any starting pattern, I struggled to produce a final pattern that was convincingly similar to my experimental results. The programme seemed to squirm away from where I wanted to go ...But it is precisely the limitations on what a model can do that gives it value; if you cannot match your model to the data, one of them must be wrong and you have something to learn. The process of 
bridging that gap provides the value and the excitement of new discovery (Bowen et al 2018).

\section{4. 'CONNECTOMICS'}

I think Jeremy was spot on when, later, he compared his own working method to that of an artist wrestling with the constraints of a medium (whatever it might be) in a creative act that brings out novelty and insight. You will understand, therefore, why I was eager to know what Jeremy, as a leading scientist and biological mathematician, might make of my Islamic conjecture. Once I'd plucked up sufficient courage to ask him, he emailed the following:

\begin{abstract}
I like the Islamic parallel. I see it more as posing a question than a model of what might exist in reality (if only we could see it). In my view, crossing point numbers and connection 'straightness' will probably turn out to be a lot more complex than the intricacies of a single Islamic pattern. How many neurons does a given neuron actually connect with locally? If the answer were known, you could envisage a variety of textures that might vary across different brain regions, so there would need to be more than one pattern type.
\end{abstract}

Clearly, my conjecture was not a conclusion but, potentially, just another step towards making the invisible visible.

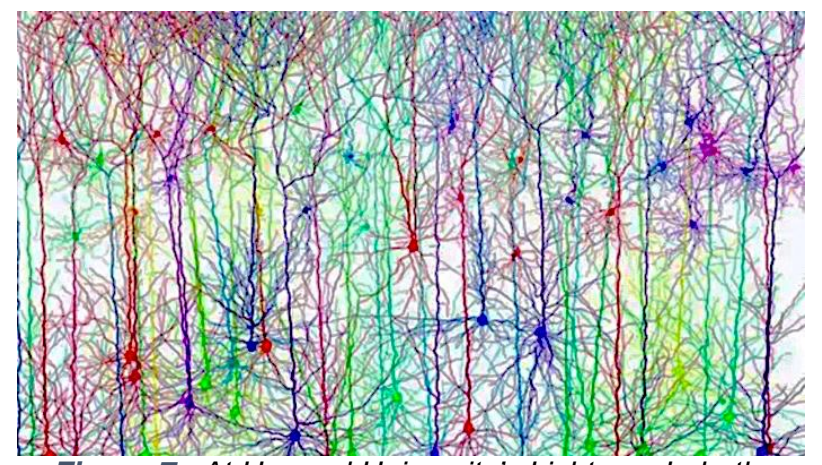

Figure 7: At Harvard University's Lichtman Lab, the neuroscience of 'connectomics' enables every synaptic connection between nerve cells in the brain to become visible.

In making his comments, Jeremy's emphasis was on 'connections' and the extent to which any given pattern can facilitate the myriad of connections that underpin the workings of the human brain. I now discover that, at Harvard University's Lichtman Lab, the idea that connections, or links, are everything in cognition has sparked off a new field of neuroscience called 'connectomics'. It involves a novel means of cutting brains into very thin slices which, through images acquired at unprecedented speed by a new type of electron microscope, enables every synaptic connection between nerve cells to become visible. Glimpses of the brain's intricate architecture coming out of this work reveal networks of a greater complexity than has ever previously been imagined (Figure 7). But, as Edward Ashford-Lee comments: 'It's this very complexity that casts doubt on whether the neuroscience of connectomics can ever explain anything; at least, with the current state of technology for acquiring and analysing the data' (Ashford-Lee 2020).

\section{THE PARADOX OF BIG DATA}

As long ago as 2014, Jeff Lichtman, Department of Molecular and Cellular Biology \& Center for Brain Science, Harvard University, described the daunting challenge posed by the data outputs of connectomics: '...it produces big data, unprecedented quantities of digital information at unprecedented rates that requires, as with genomics at the time, breakthrough algorithms and computational solutions' (Lichtman et al 2014). Even now, neuroscience still largely lacks the organising principles or a theoretical framework for converting brain data into fundamental knowledge and understanding. Big data presents a paradox; in the process of gaining ever-more information on what we are seeking, we lose sight of where we are going. As cognitive scientist Yves Frégnac, French National Centre for Scientific Research, puts it:
Nowadays, we are drowning in a flood of information. Paradoxically, all sense of global understanding is in acute danger of getting washed away. Each overcoming of technological barriers opens up a Pandora's box by revealing hidden variables, mechanisms, and non-linearities, adding new levels of complexity (Frégnac 2017).

If ever a project was in need of a new vehicle for research and innovation, it is connectomics. In saying this, I'm not intending to underrate, in any way, the spectacular work generated by the Lichtman Lab; any project that has developed automated methods to both generate and analyse digital data sets that reveal all the neural wiring between nerve cells, and many subcellular details of brain tissues, deserves respect and serious consideration. But connectomics has reached an impasse. The project serves to remind us that digital computation is the most potent invention that the human brain has ever come up with; its advances are now surging ahead of our more slowly evolving human biological brains to keep up and understand what technology is capable of telling us. As of a few years ago, Jeff Lichtman's view, lacking a clear idea on what parts of the connectomics data trove will ultimately be relevant, was to err on the side of getting too much data rather than just the data that answers a particular question. But this view serves only to compound the big data problem by increasing exponentially the requirement 
for the storage and analysis of massive amounts of digital information. Of course, there is every chance that, as time goes on, the natural co-evolution of human biology and machine technology will bring both elements back into a state of realigned synchronisation. Until such a time, if there is an answer, it lies in the continual testing of data against a preconceived model (or conjecture); if they can't be matched, one of them must be wrong and you have something to learn (ie. the process of discovery described by Jeremy Green in Section 3 above).

I believe my Islamic conjecture, in leaping the barriers imposed by big data, might provide just such a case.

\section{THE VALUE OF CONJECTURE}

It was by formulating my conjecture of the brain's neural network as an Islamic pattern that I posed a question. In other words, without claiming that my expression of the brain's intricacies was anything more than 'a leap into the dark', it served a purpose by bringing together many strands of ambiguity to produce what I call a 'plateau of lucidity'. As an artistic creation rather than an outcome of big data analysis, such a plateau cannot be regarded as being, in itself, scientifically valid, but this doesn't prevent it providing insights on further lines of research or scientific discovery which, in turn, lead to further plateaux of lucidity. By this means, an artist's sometimes disruptive interjections generate a process of continuous feedback whereby, at each iteration of the loop, as further elements of ambiguity are generated by evolving technology, a yet closer inspection of the brain's network is facilitated which, in turn, demands a revised conjecture leading to a more informative plateau of lucidity. And so the process goes on.

I've applied the above conjectural process, in past years, when, as an architect, l've been charged with solving intractable problems concerned in matching the complexities and conflicts of organisational (or Company) life against the inflexibilities of building 'shells'. To some people, it comes as a surprise that Stafford Beer placed the Company in the category of his 'exceedingly complex' systems but, from my own experience, I know he was right. The challenge of finding appropriate ways of resolving, within interior environments, office user's seemingly irreconcilable demands for diversity versus conformity and flexibility versus stability underpins the conflicts that have to be faced up to and solved by procedures involving continuous feedback (Trickett 1992). Such paradoxes, alongside the necessity of acknowledging social needs as an ever changing process, serve to define the complexities of the Company, where order must somehow emerge from apparently unassailable diversity. (I have described one such case involving fundamental changes at the
Financial Times, London, in a previous EVA paper 'A Cybernetic Clarion Call to the Arts' Community' (Trickett 2019).)

Can experience of the Company provide lessons on how to tackle the seemingly irreconcilable demands made by other exceedingly complex systems? To examine this question, I'm turning again to the exceedingly complex system of the brain.

\section{COMMON CHARACTERISTICS OF 'EXCEEDINGLY COMPLEX' SYSTEMS}

Exceedingly complex systems appear to have common characteristics; they are composed of a large number and a great variety of components which together produce 'a mode of organised interaction and a functional coherence that transcends the intrinsic capacities of each individual component' (Sporns 2011). I am indebted to Olaf Sporns for that definition; as a foremost expert on brain connectivity, he regards the brain's complexity as being about patterns that facilitate structural or functional organisation, cooperation processes and dynamic diversity. He makes the point that the seemingly irreconcilable demands of segregation versus integration, as placed on the brain's neural processing systems, have somehow to be realised within a single architecture. This is a problem that sounds familiar, does it not? I've referred to a similar paradox in my description of tackling the problems of the Company. Paradoxes and the problems involved in resolving them are another common characteristic of exceedingly complex systems.

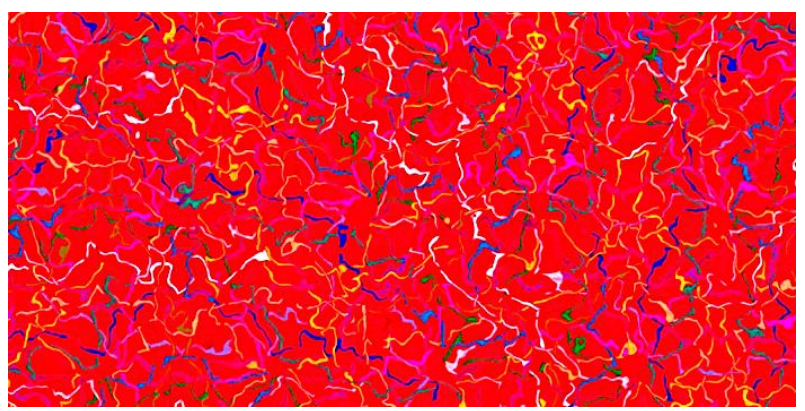

Figure 8: In this still from the quickly moving imagery of 'Brainwaves', it's possible to perceive the brain's axons and neurons, nested across multiple layers, giving indications of neuro cognitive networks, individual brain regions and even single neurons.

In my conjecture on the brain's intricate architecture (see Section 3 above), I'm proposing a specific type of structural connectivity that appears to favour and enable the emergence of highly complex and variable dynamic patterns - so variable, in fact, that, at first glance, they give no sense of commonality or coherence (Figures $6 \& 8$ ). But the truth is that, in spite of appearances, each pattern conforms strictly to the same underlying Islamic geometry. Nature's 
organic method for embracing order versus disorder and segregation versus integration is not the same as an Euclidian (or even an Islamic) tight-rope of conformity; it allows for the flexible composition and decomposition of components and interactions, on several hierarchical levels which, at one and the same time, can take on many forms of expression.

My way of communicating these conjectures and ideas on complexity is Visual Music. It's a medium that enables me to explore, without inhibition, their artistic potential and to give some sense of the science which underlies them. I'm always surprised by the results; they are never what I expect.

In the case of the quickly moving imagery of 'Brainwaves', I believe it's possible to perceive the brain's axons and neurons, nested across multiple layers, giving indications of neuro cognitive networks, individual brain regions, specialised neural populations and even single neurons (Trickett 2021a). Am I deceiving myself or have I entered the world of fantasy, I wonder? Possibly I am fantasising, but remember Nabokov's poetic words, included in his 'Butterflies', where he stated: 'There's no science without fantasy and no art without fact' (Nabokov 2000). To my mind, there's enough factual reality in my piece of Visual Music for me to make a plausible claim that it provides a valid (albeit disruptive) artistic insight on how our brains' might work. Experts on brain connectivity understand the challenges the brain has to meet but they don't know how it does it. But they do know that, in one form or another, the brain's complexity is based on network interactions, on patterns of functional or effective connectivity that are constrained by anatomy ie. the brain's gyri (hills) and sulci (valleys)(Figure 6). In Brainwaves I'm aiming to depict, through musical note groupings and quickly moving visual imagery, a pattern of multi-dimensional complexity that represents the brain's answer to the persistent challenges of a variable and only partly predictable environment.

\section{CONJECTURAL COINCIDENCE?}

The proponents of conjectures (or models) must accept the almost inevitable transience of their ideas; only a few will give some indication that they merit thorough and often expensive investigation to become, eventually, the basis of general scientific theory. In support of such an ideas-led process of discovery where conjectures come first, Yves Frégnac quotes from the letters of Yakov llich Frankel:

A good theoretical model of a complex system should be like a good caricature. It should emphasise those factors which are most important and should downplay the inessential details..... Since one does not really know which are the inessential details until one has understood the phenomenon under study....one should investigate a wide range of models and not stake one's life (and one's theoretical concept) on one particular model only (Frégnac 2017).

'Good caricatures' have meaning because they bring to the surface 'the not quite obvious', they offer a distortional twist that can throw some new light on a problem obscured by a surfeit of information or burdensome detail. Such characterisations, plateaux of lucidity as l've called them earlier, which can take place at multiple instances during a research and development process, can be conceived not only by the scientists and technologists involved but, also, on occasion, by new media artists with a proven creative curiosity brought in for the purpose. I hope, in this paper, that l've succeeded in revealing the value of this collective approach to releasing bottlenecks in large-scale search studies particularly as they impact on investigations into exceedingly complex systems.

It's on the subject of 'the brain' that a vast array of projects is taking place world-wide, in Australia, Europe, the United States, Israel, Japan and China but, still, an understanding of how the structure of the brain's network determines its function remains elusive. But there are some signs of progress.

As an outsider, I see the path to uncovering the mysteries of the brain's network proceeding from biological discovery to topological calculation and then to some form of geometric rationalisation. Following on from the immense amount of information gathered through connectomics, recent conjectures, spun off by mathematics in the form of algebraic topology, are beginning to unravel the complexities of many components of an exceedingly complex system. What remains to be discovered is a new type of geometry which, in putting all the parts together, can facilitate a comprehensive understanding of a multi-dimensional synaptic network capable of significant variation in accommodating ever changing patterns of neural density, as they occur in different regions of the brain.

Recent, multi-authored papers, have defined the existence of all-to-all connected nodes, or structural units, within the brain's network called cliques (Reimann et al 2017, Sizemore et al 2018). (I'm regarding cliques as being sets of neurons and their synaptic connections.) It's through this clique architecture that topographical cavities also have been detected. Using the language of algebraic topology, cliques become simplices or hypertetrahedrons which, acting in dimensions from $2 \mathrm{D}$ to $11 \mathrm{D}$, can be expressed as directed graphs (Figure 9A). It's in this form that cliques have some passing 
resemblance to the hubs of my Islamic parallel (Figure 5). The fact that the hubs of the Islamic pattern appear to be the visual equivalent of 11D simplices must be regarded as being coincidental, of course, but nonetheless remarkable. I'm encouraged in this idea by reports of in vivo investigations that have noted 'starlike' configurations within the brain's network; stars appear to be useful configurations for achieving fast communication along short paths and between the 83 regions of the brain (Sizemore et al 2018).

Directed cliques describe the flow of information in the network at a local level while cavities provide a global measure of information flow in the whole network. Together, the two notions of dense cliques and information distributing cavities provide a picture of a system that performs complex computations by decomposing information in coherent pieces to enable cross talk between different regions of the brain. In its simplest form a cavity can be formed within a geometric object defined by two tetrahedrons (Figure 9B). At the other extreme, the formation of a net of tetrahedra, guided by biological principles, can generate a vast number of potential synaptic communication routes (Figure 9C). In all, the mathematical conjecture I've sketched out here begins to provide some glimmerings of insight on how the brain's network, across different regions, can vary in its sparseness and strength through a regular pattern of structural connectivity able to cope with randomness another paradox that has to be accommodated by the brain's intricate architecture.

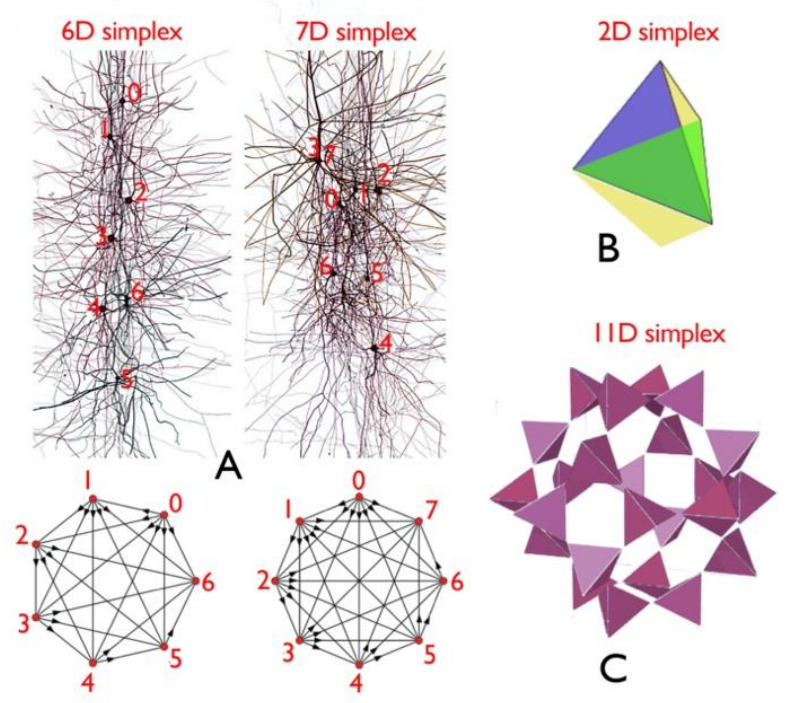

Figure 9: (A) Simplices of dimensions 6 \& 7 represented as directed graphs (bottom) and as reconstructed

microcircuits (top). (B) Simplex dimension 2 realised as a geometric object containing a 3 dimensional cavity.

(C) Realisation of an 11D simplex (similar to the hubs in Figure 5) where a net of tetrahedrons (shown in part) forms a multi-dimensional cavity. [Diagram A courtesy of Reimann et al (2017).]

\section{CONFRONTING CLIMATE CHANGE}

My story of investigations into the brain is littered with paradoxes, conflicting demands that appear to be unresolvable within a single architecture. They characterise the problems posed by an exceedingly complex system which, in spite of all difficulties, still show signs of being fixable. Challenges to understanding presented by 'the brain' may differ radically from the daunting task of tackling 'climate change' but, as l've related, through the adoption of novel and imaginative processes of research, the seemingly impossible can be tamed. My purpose, in this paper, is to lay stress on the importance and potential value of involving new media artists in such programmes of research and innovation; they have a significant part to play.

Recent ramifications of climate change have pinpointed the urgency for taking action, which requires that the two great ways of knowing, understanding and discovery - art and science become creatively harnessed together as never before. In my own experience, l've found that the creative processes of art and science are similar to the point of being virtually synonymous; they give credence to what George Steiner has called a 'code of the collective'. This can be described as a creative environment where new media artists think and create like scientists, scientists think and create like new media artists and the digital tools of discovery and expression that they each use are one and the same. When Bill Gates, in his recent book 'How to Avoid Climate Disaster' tells us that to find solutions 'we'll need biology, chemistry, physics, political science, economics, engineering and other sciences' he's missing out the other crucial $50 \%$ (Gates 2021). Maybe, the recognition of this movement towards the collective has been slow in coming but, now, at this critical turning point in civilisation, we have every reason to follow George Steiner's advocacy when he states:

\footnotetext{
The arts and humanities, where traditionally singularity and solitude are of the essence, must join scientific discovery and technological investigation by taking place in a spirit of partnership and sociability (Steiner 2001).
}

In recognition of this gradual blurring of the boundaries between art and science, occurring over the last 30 years or so, the European Commission (EC) has set up its S+T+ARTS (Science + Technology + Arts) initiative. It's a progressive initiative that aims to support collaborations between artists, scientists, engineers and researchers to develop more creative, inclusive and sustainable technologies. Underlying STARTS is the belief that 'in addition to scientific and technological skills, one of the critical skills needed for innovation to happen, and to be of value to society, is creativity'. Further 
'since creativity is rooted in artistic practices, the expertise and practice of artists can directly drive and influence innovation in technology' (STARTS 2020). It's through STARTS that the arts and humanities can gain entry to the EC's major programs of research and innovation (ie. Horizon 2020 and Horizon Europe 2021 - 2027). Horizon Europe is concerned specifically in five mission areas of which four are concerned either directly or indirectly in climate change as it affects the environment, oceans, cities and soil (European Green Deal 2019)'. The exhortation I issued, in 2019, under the title 'A Cybernetic Clarion Call to the Arts' Community' has already sparked off a determination to act amongst the EVA International community (Trickett 2019). Now, through STARTS and opportunities offered by the EC's initiatives, new media artists can be expected to join their scientific and technological counterparts in generating and developing ideas that can not only transform our use of nature's resources but, also, act as a behavioural trigger in promoting awareness and changing attitudes towards the ravages of climate change.

\section{REFERENCES}

Aleksander, I. (2000) How to Build a Mind. Weidenfeld \& Nicolson, London.

Ashford-Lee, E. (2020) The Coevolution: The Entwined Futures of Humans and Machines. The MIT Press, Cambridge, Massachusetts.

Beer, S. (1959) Cybernetics and Management. English Universities Press, London.

Bowen, P. J., Trickett, T., Green, B. A., and Lomas, A. (2018) Turing's Genius: Defining an apt microcosm. In: Bowen, J.P., Weinel, J., Diprose, G., and Lambert, N. (eds), EVA London 2018 (Electronic Visualisation and the Arts), London, 9-13 July 2018, pp.155-162 BCS, London. DOI:10.14236/ewic/EVA2018.31

European Green Deal (2019). Online: https://ec.europa.eu/info/sites/info/files/european-greendeal-communication en.pdf (retrieved March 2021).

Frégnac. Y. (2017) Big data and the industrialization of neuroscience: A safe roadmap for understanding the brain? Science 358(6362), pp.470-477. DOI: 10.1126/science.aan8866

Gates, B. (2021) How To Avoid a Climate Disaster. Allen Lane, part of Penguin Random House UK.

Kauffman, S. (1995) At Home in the Universe: The Search for Laws of Complexity. Penguin Books, London.

Lichtman. J. W., Pfister. H. W., and Shavit N. (2014) The big data challenges of connectomics. Nat Neurosci 2014 Nov.17(11), pp.1448-1454.

https://www.ncbi.nlm.nih.gov/pmc/articles/PMC4412267/ (retrieved February 2021).
Nabokov, V. (2000) Nabokov's Butterflies: Unpublished and Uncollected Writings, R. M. Pile and B. Boyd, eds. Beacon Press, Boston, MA.

Reimann, M. W., Nolte, M., Scolamiero, M., Turner, K., Perin, R., Chindemi, G., Dłotko, P., Levi, R., Hess, K., and Markram, H. (2017) Cliques of Neurons Bound into Cavities Provide a Missing Link between Structure and Function. Front. Comput. Neurosci. 11:48. DOI: 10.3389/fncom.2017.00048R

Sizemore, A., Giusti, C., Kahn, A., Vittel, J., Betzel, R., Bassett, D. (2018) Cliques and cavities in the human connectome. J. Comput. Neursci. 44, pp. 115-145. https://doi.org/10.1007/s10827-017-0672-6 (retrieved March 2021)

Sporns, O., (2001) Networks of the Brain. The MIT Press, Cambridge, Massachusetts.

STARTS collaboration toolkit (2020). Online: https://www.starts.eu/media/uploads/starts-toolkit13july2020.pdf (retrieved March 2021).

Steiner, G. (2001) Grammars of Creation. Yale University Press, New Haven and London.

Tofano. C. (2019) Digital artist Oliver Gingrich talks to Carla Tofano in Metralla Rosa Ep 03. [Youtube video]. https://www.youtube.com/watch?v=HGSepKJUbw\&vl=en (retrieved February 2021).

Trickett, T. (1992) Design at Work. Facilities, 10(2), pp 913. DOI: https://doi.org/10.1108/EUM0000000002176 (retrieved March 2021).

Trickett, T. (2015) The Legacy of Sci-Art. Online: https://sites.google.com/site/researchthelegacyofsciart/h ome (retrieved February 2021).

Trickett, T. (2016) Turingalila: Visual Music on the Theme of Morphogenesis [Youtube video]. https://youtu.be/M4kl8WMaov8 (retrieved February 2021).

Trickett, T. (2018) An astonishingly intricate architecture: Visual Music of the Brain and Mind. Technoetic Arts: $A$ Journal of Speculative Research 16(1), pp. 5-22. DOI: 10.1386/tear.16.1.5_1

Trickett, T. (2019) A Cybernetic Clarion Call to the Arts' Community. In: Weinel, J., Bowen, J.P., Diprose, G., and Lambert, N. (eds), EVA London 2019 (Electronic Visualisation and the Arts), London, UK, 9-11 July 2019, pp.368-375. BCS, London. DOI: http://dx.doi.org/10.14236/ewic/EVA2019.69 (retrieved March 2021).

Trickett, T. (2021a) Brainwaves [Youtube video]. https://youtu.be/wYxzimKghko (retrieved March 2021).

Trickett, T. (2021b) The Making of Sci-Art. Leonardo, 54 (4), June 2021. 